\title{
Study of the fire dynamics in a burning car and analysis of the possibilities for transfer of fire to a nearby vehicle
}

\author{
Angel Terziev ${ }^{1, *}$ \\ ${ }^{1}$ Department "Power Engineering and Power Machines", Technical University of Sofia, 8 Kliment \\ Ohridski blvd., 1000 Sofia, Bulgaria
}

\begin{abstract}
A full scale experiment was carried out on the process of vehicle combustion and the ignition of an adjacent one. For this purpose, specialized measuring equipment (thermocouples and infrared camera) is used to determine the temperature field of the burning car and nearby vehicle. The burning car has 16 thermocouples mounted on it and one thermocouple mounted on the adjacent car in order to examine the heat transfer process. The temperature field between cars at different points of time is detected by an infrared camera, with a clear change in the temperature gradient in the presence of wind. It is one of the main reasons for the increased momentum of heat transfer. The research shows that with the available combustible load of the car $(2,1 \mathrm{MW}$ or around the average for the currently produced cars), the ignition of the neighbouring vehicle is expected around 14 minutes after the ignition of the main vehicle, with the ignition zone being in the engine compartment. Important information was obtained for both the dynamics of the burning vehicle and the temperature field between the two cars.
\end{abstract}

\section{Introduction}

There are many reasons for the occurrence of a fire in road transport vehicles. Most often they are deducted to a road traffic accident, gaps/failures in the vehicle's systems or as a result of vandalism. The fire may occur both during vehicle movement and in a parked state.

The dynamics of the fire depends on both the fuel load of the vehicle and the environmental parameters. The development of fire in a burning vehicle in open space depends mainly on outside air parameters such as wind speed and temperature. In limited spaces (such as underground parking and garages), the development depends both on the available amount of oxygen in the air and on the availability of ventilation systems.

In literature, the research of burning vehicles in a limited space is common. An analysis of the reasons for the occurrence of a fire in a confined space is presented in $[1,2]$ and concrete measures to prevent the occurrence of a fire, as well as a risk assessment, are presented. Paper [3] presents a full scale flame fire experiment and a study of the possibilities for transfer of fire to a nearby vehicle. The radiant heat flux is measured with a heat flux gauge installed $5 \mathrm{~m}$ away from the car fire. The temperature of the flue gases in 
the vicinity of the vehicle has been measured while being calculated using the indirect calculation method. The influence of mechanical systems on the development of fires of vehicles in garages (indoor spaces) is presented in [4, 5]. Paper [6] is an analysis of the possible effect of passive fire protection techniques on the peak heat release rates and temperature inside the tunnel. The impact of the effects studied provides information on enhancing the fire safety in road tunnels.

In recent decades, there has been a growing interest in the investigation of fires in cars using numerical methods. In paper [7, 8] numerical approaches are presented in modelling of burning vehicles in garages. The studies show that affected by ventilation systems, the fire develops rapidly resulting in the most rapid oxygen consumption followed by early extinction of the fire. In the presence of fresh air supplied by the intake ventilation system re-ignition takes place at an accelerated rate. The sensitivity of the CFD results to the input parameters is highlighted. As a conclusion it is stated that in a 4MW vehicle the supplied ventilation rate should not exceed $1,1 \mathrm{~m} / \mathrm{s}$ in order to limit air with a high concentration of oxygen to accelerate the combustion process.

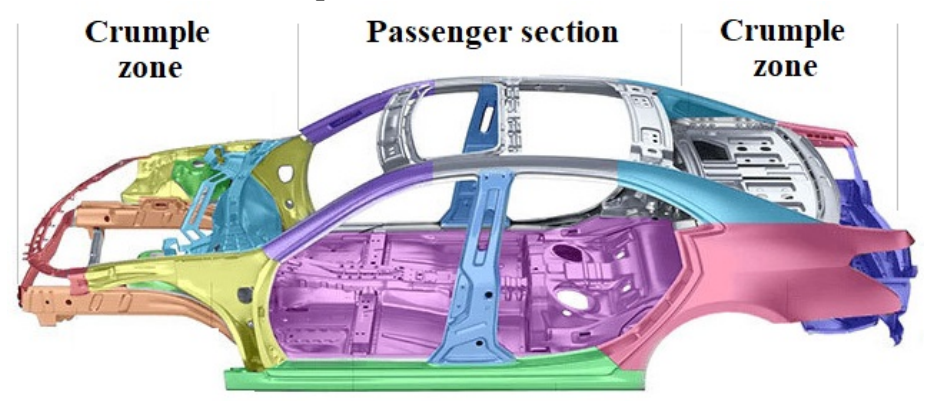

Fig. 1. Separated zones in the event of a fire [10]

The distribution of the fire in a car depends on a number of factors - the location of its ignition (engine compartment, passenger compartment, luggage compartment) (Figure 1), weather conditions, the presence of obstacles around the vehicle, the location of the vehicle (open spaces or Indoors), the characteristics of the vehicle, etc.

\section{Experimental study}

Experimental study is performed with a VW Golf Passat, fully-working, manufactured in the year 2000 (Figure 2). A "Peugeot" car was located at a distance of $0,8 \mathrm{~m}$ away from the VW Golf. Based on the data presented in Table 1 regarding the combustion characteristics of the materials of the chosen vehicles it has been estimated that the combustion load is about 2,1 MW.

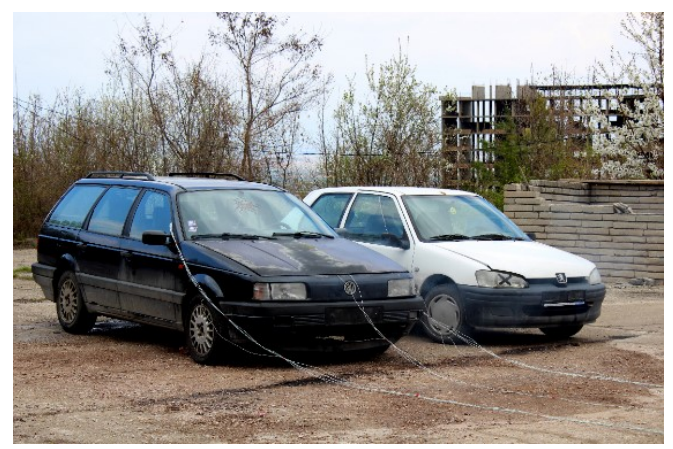

Fig. 2. Models and positioning of cars during the experiment 
Table 1. Typical combustible material properties of the proposed cars

\begin{tabular}{|c|c|c|c|}
\hline $\begin{array}{c}\text { Combustible } \\
\text { materials }\end{array}$ & $\begin{array}{c}\text { Basic Composite } \\
\text { Material }\end{array}$ & $\begin{array}{c}\text { Ignition } \\
\text { point }\left[{ }^{\circ} \mathbf{C}\right]\end{array}$ & $\begin{array}{c}\text { Oxygen } \\
\text { Index, [\%] }\end{array}$ \\
\hline Engine compartment & Polypropylene & 211 & 19 \\
\hline Seats & Polyurethane foam & 205 & 17 \\
\hline Console shell & Polyvinyl chloride & 238 & 20 \\
\hline Tires & Rubber & 289 & 38 \\
\hline
\end{tabular}

\subsection{Measuring equipment used during the experiment}

Various measuring equipment was used during the experiment. The multifunctional Testo 435-4 meter is used to determine the outside air parameters. It is equipped with sensors for measuring wind speed, temperature, humidity and atmospheric pressure. Table 2 provides information on the type and technical characteristics of the measuring equipment.

Table 2. Summary technical specification of a multifunction meter - Testo 435-4

\begin{tabular}{|c|c|c|c|}
\hline Probe & Parameter & Measuring Range & Accuracy, \% \\
\hline Humidity probe & Humidity & 0 to $+100[\% \mathrm{rH}]$ & $0,1[\% \mathrm{rH}]$ \\
\hline Pitot tube & Differential Pressure & 0 to $25[\mathrm{hPa}]$ & $0,01[\mathrm{hPa}]$ \\
\hline Hot wire anemometer & Velocity & 0 to $20[\mathrm{~m} / \mathrm{s}]$ & $0,01[\mathrm{~m} / \mathrm{s}]$ \\
\hline Hot wire anemometer & Temperature & -50 to $+125\left[{ }^{\circ} \mathrm{C}\right]$ & $\pm 0,4\left[{ }^{\circ} \mathrm{C}\right]$ \\
\hline
\end{tabular}

16 thermocouples have been installed to measure the temperatures during the fire in the passenger compartment. The outputs of the thermocouples were connected to two TC600 multichannel digital thermometers, with serial numbers 01648 and 01729 respectively. The thermocouple installation points are presented in figure 3. The operational range of the instruments is $0 \div 1200{ }^{\circ} \mathrm{C}$. A calibration certificate with № 18A / 12.01.2016 and 19A / 12.01.2016 was issued by Interlabe AD.
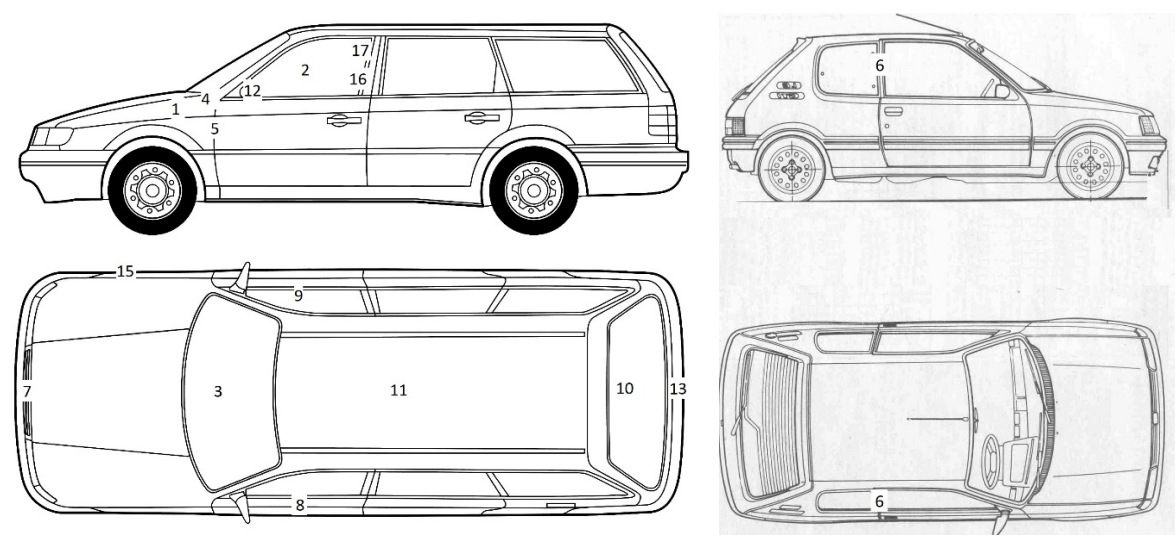

Fig. 3. Location of K type thermocouples: 1-engine compartment, 2-cup inner roof, 3-windshield, 4fuel hoses, 5-fuse box, 6 - front left door to adjacent vehicle; 7-door hatch, 8-door front left, 9-door front right, 10-spoke glass, 11-compartment floor, 12-way dashboard, 13-door luggage compartment, 14-wheel front left, 15- wheel front right, 16-front left seat. 
In addition, Infrared camera (FLIR E40) was used to capture the temperature field in front of the vehicles. The basic parameters of the measuring equipment used during the experiment are presented below:

- Resolution: 160 x 120 IR

- Spatial resolution: $2,72 \mathrm{mrad}$

- Thermal sensitivity: $<0,07^{\circ} \mathrm{C}$

- Temperature range $\mathrm{L}-20$ to $+650{ }^{\circ} \mathrm{C}$

- Spots: 33 boxes with $\min / \max$ air

- Measurement of temperature difference -3,1 Mp digital camera and one LED light

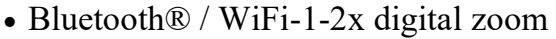

- IR area on real image.

\subsection{Experimental results}

Experimental study was performed on 06 April 2017. The collected data during the experiment show the following: wind speed varies from 0 to $5 \mathrm{~m} / \mathrm{s}$ with the average reading being $2,8 \mathrm{~m} / \mathrm{s}$. The change of temperature is in the range of 10 to $16{ }^{\circ} \mathrm{C}$. Peak values are in times when the predominant wind direction is from the burning vehicle to the measuring probe. The humidity varies from 48 to $60 \%$. Atmospheric pressure during the experiment changes in a narrow range of $925-926 \mathrm{hP}$. The change in outdoor air parameters during the experimental studies is shown in Fig. 4 a-d.
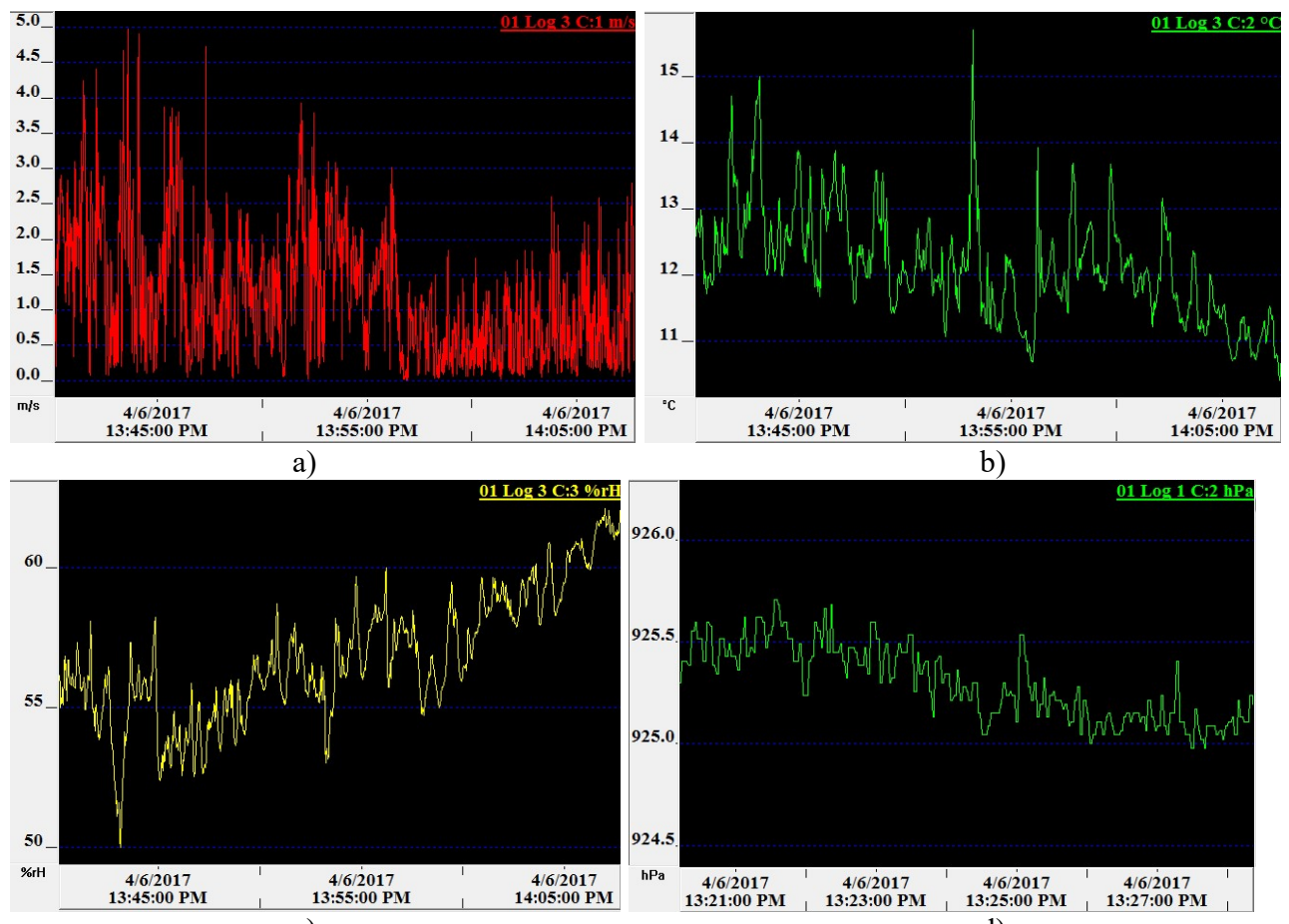

c)

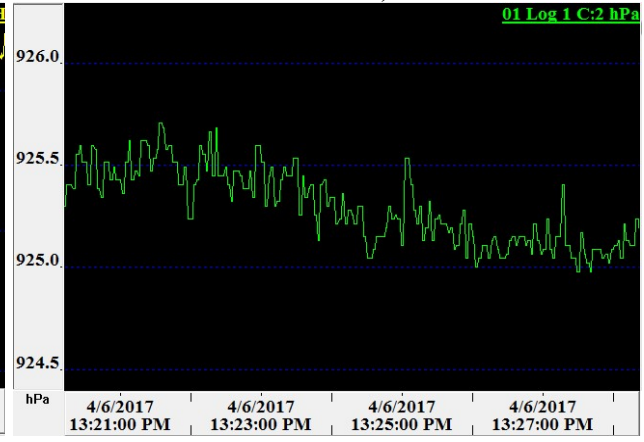

d)

Fig. 4. Collected data for ambient air: a) air velocity; b) air temperature; c) relative humidity of the air; d) atmospheric pressure 


\section{TE-RE-RD 2019}

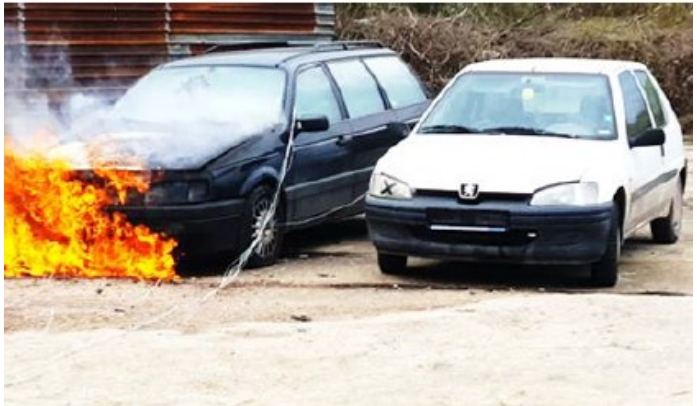

a)

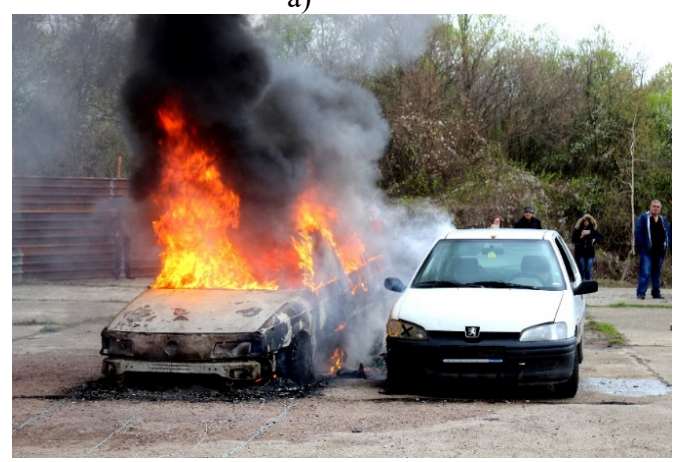

c)

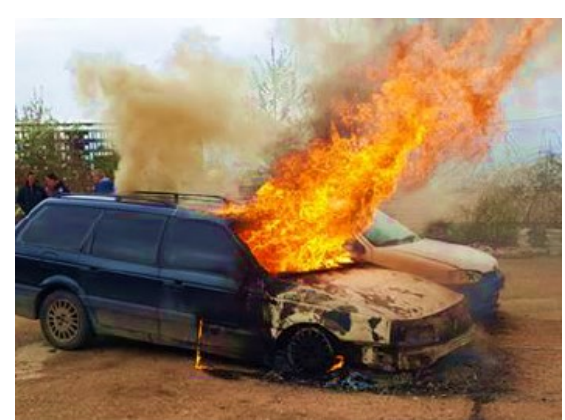

b)

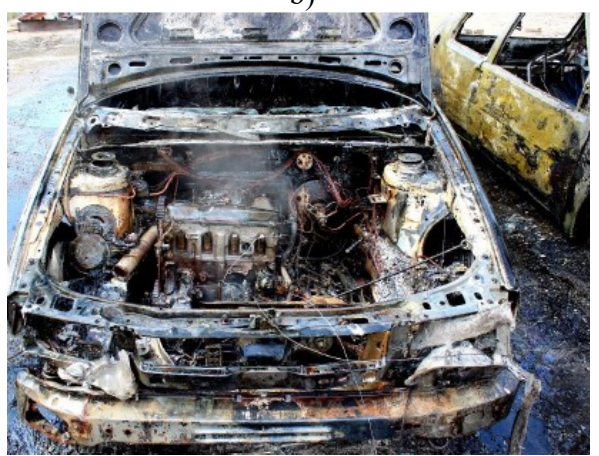

d)

Fig. 5. Instant photographs during the fire: a) 9 min after ignition; b) 15 min after ignition; c) 22 minutes after ignition; d) after the test

Figures $6 \mathrm{a}$ and $\mathrm{b}$ show information about the temperature change during the engine fire and fuel system fire. These two areas are mentioned because they are directly in front of the infrared camera that shoots the fire. The impression is that after the fire occurs, the values recorded with the FLIR camera are lower than those measured with the thermocouples. This is due to the fact that the surface temperature is measured with the camera, whereas the values measured with the thermocouples are for the respective point.

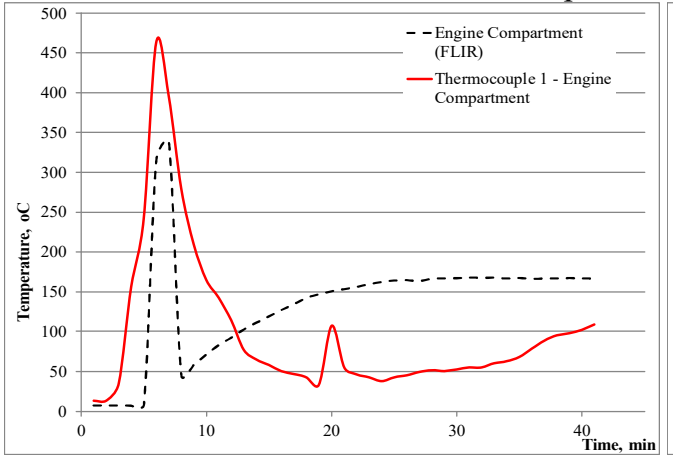

a)

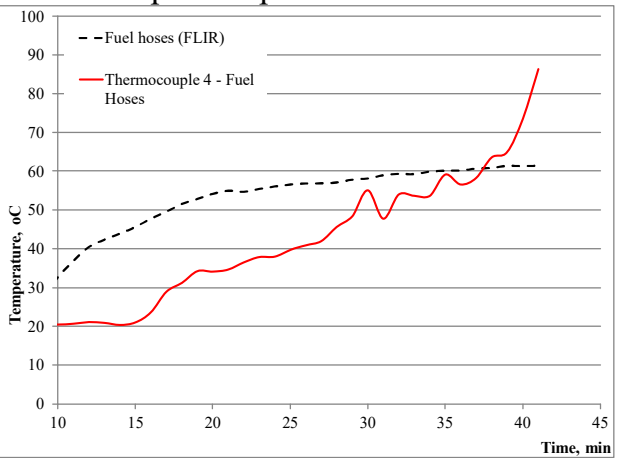

b)

Fig. 6. Temperature distribution a) zone Engine compartment; b) zone Fuel fuses

The results obtained by using the thermal imaging camera to study the fire provided enough detailed information about its development. The horizontal axis in Figure 7 represents the distance between cars respectively temperature profiles of the air between the two vehicles. Figure $7 \mathrm{a}$ the high temperature of the burning vehicle is clearly visible. A heat flux from the burning car is detected on the right side of the diagram. Figure $7 \mathrm{~b}$ shows the 
temperature profile of the air between the two vehicles in the period of 20 minutes. Here, with the thermal imaging camera, a reversal of the temperature profile is detected as a result of a change in the flame direction due to wind. Figure $7 \mathrm{c}$ shows a temperature equalization between the two vehicles, respectively the ignition of the adjacent vehicle. Figure $7 \mathrm{~d}$ shows an analogous situation like the one in Figure $7 \mathrm{~b}$ (the case of a strong side wind), but unlike the previous case, here the velocity profile is considerably more aligned.
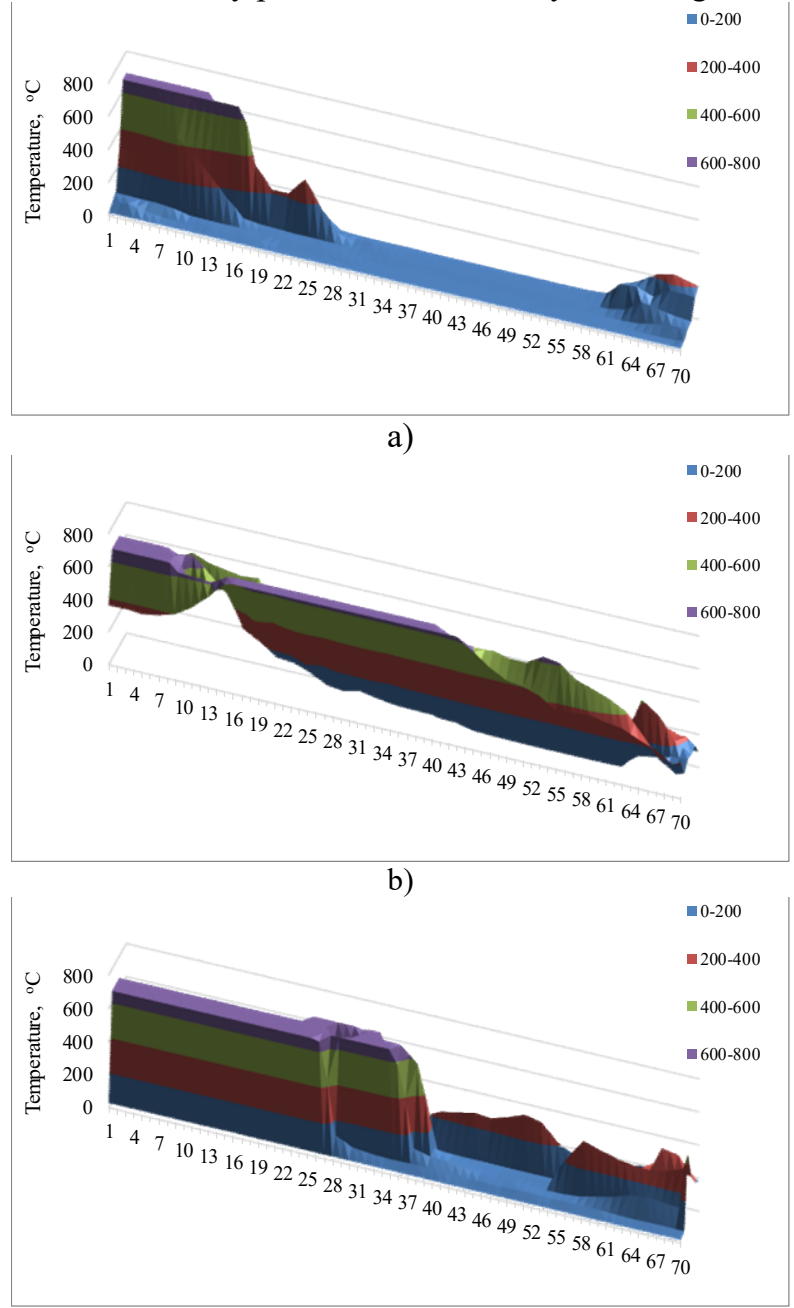

c)

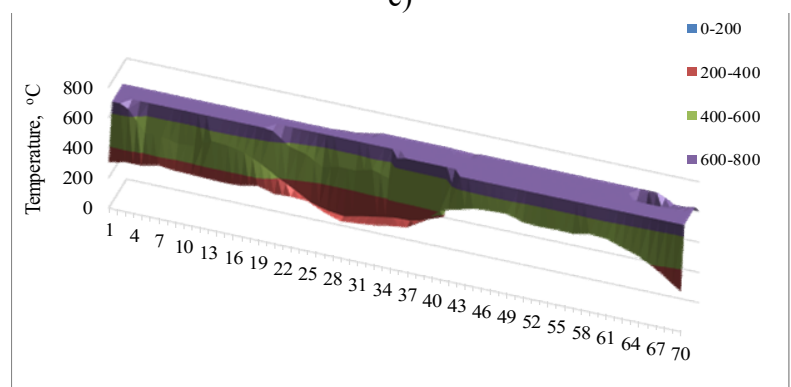

d)

Fig. 7. Temperature distribution a) zone Engine compartment; b) zone Fuel fuses 
Fig. 8a-b give information from the thermal imaging camera for the distribution of the temperature field around the burning vehicle. The clearly identifiable are the temperature fields when the two different prevailing wind directions are registered.

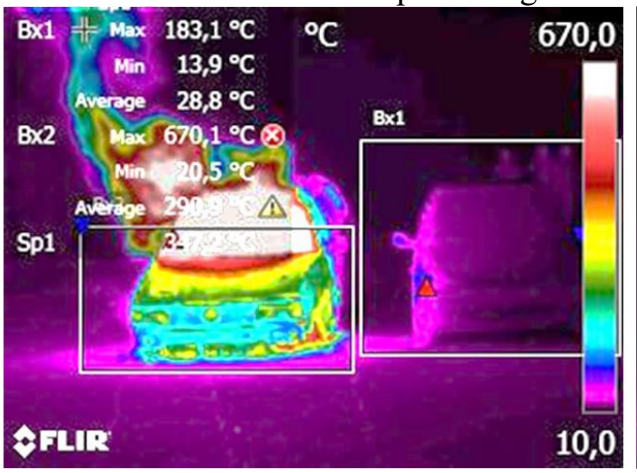

a)

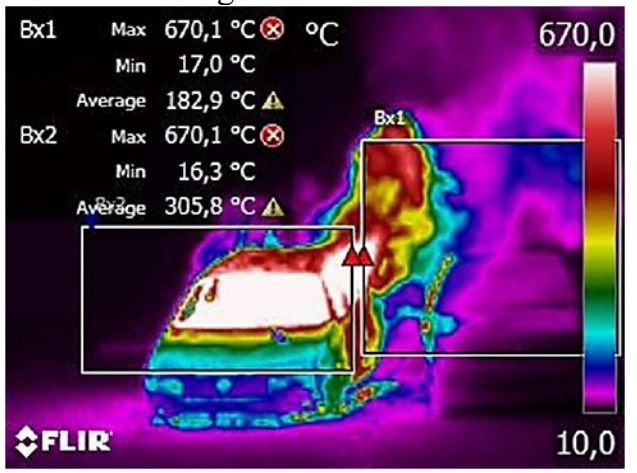

b)

Fig. 8. Temperature field around burning car captured with infrared camera: a) prevailing wind direction from east, b) prevailing wind direction from west

Figure 9 shows information about the temperature change of the two adjacent car doors (thermocouples 6 and 8). Once the fire starts in the engine compartment, it begins to take over the vehicle gradually. Initially, smoke begins to fill the vehicle's body and increase its temperature. The ignition of the individual elements begins after reaching their flash point. Thus, the door to the driver (made of acrylic fibers) is ignited at a temperature of $560{ }^{\circ} \mathrm{C}$. A temperature gradient is apparent from the figure, which for a short time exceeds $800{ }^{\circ} \mathrm{C}$. Upon reaching this peak, the temperature slowly began to decrease, with a slight increase 36 minutes later due to the cracking of the rear window of the vehicle and the entry of outside air with higher oxygen content. Burning of the left door of the vehicle points to a high temperature, which implies an increased heat transfer through radiation heat exchange. This is the reason for the sudden increase in the door temperature of the neighbouring vehicle. This rapid change is also due to the presence of wind, which further intensifies the heat transfer process (Figure 8b). After 14 minutes, there is a decrease in temperature of the left door of the burning vehicle and an increase in the temperature of the neighbouring door due to its ignition. The conclusion from the figure is that given the burning load of the vehicle, the ignition of the neighbouring car, when the distance is $0,8 \mathrm{~m}$, is in the order of 14 minutes.

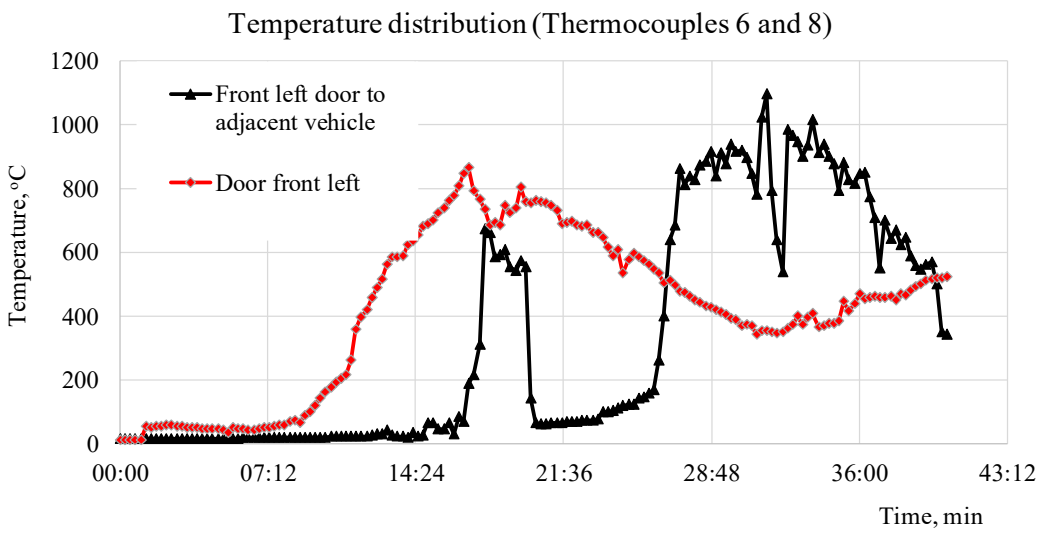

Fig. 9. Experimental data from the temperature change of the two adjacent car doors (thermocouples 6 and 8) 


\section{Conclusion}

The dynamics of fire in vehicles positioned in open space differs significantly from the one in closed space (underground parking lots and garages). The environmental parameters play a major role in the development of the fire. The presence of wind significantly changes the behaviour of the combustion process as well as the direction of radiation heat exchange. In the presence of winds up to $5 \mathrm{~m} / \mathrm{s}$ the ignition of the neighbouring vehicle may occur no later than 14 minutes, of course taking into account the fuel loading of the cars, which in this case is about 2,1 MW. The resulting distribution of the temperature field around the vehicle in a fire is important for analysing the dynamics of the fire and is extremely important when the vehicle is to be extinguished.

\section{Acknowledgements}

The author would like to thank the Research and Development Sector at the Technical University of Sofia for the financial support.

\section{References}

1. Moss PJ., et al, Incremental fire analysis (IFA) for probabilistic fire risk assessment. In: Proc. 23rd Australasian Conference on the Mechanics of Structures and Materials (ACMSM23), 9-12 December 2014, Byron Bay, NSW, Australia, 2014, pp. 707-712

2. Shintani Y, et al, Experimental investigation of burning behavior of automobiles, 6th Asia-Oceania Symposium on Fire Science and Technology, Korean Institute of Fire Science \& Engineering, 17-20 March 2004, pp. 618-629.

3. Dayan Li, Guoqing Zhu, Hui Zhu, Zhichao Yu, Yunji Gao, Xiaohui Jiang, Flame spread and smoke emperature of full-scale fire test of car fire, Case Studies in Thermal Engineering, 10, 2017, Pages 315-324

4. I. Antonov, R. Velichkova, K. Grozdanov, S. Antonov, M. Uzunova, I. Abbassi, Fire extinguishing system in large underground garages, Advances in Science, Technology and Engineering Systems Journal, 2, No 3, pp. 221-226 (2017)

5. B. Merci, M. Shipp, Smoke and heat control for fires in large car parks: Lessons learnt from research?, Fire Safety Journal, 57, 2013, Pages 3-10

6. Mukesh Singh Tomar, Shashank Khurana, Impact of passive fire protection on heat release rates in road tunnel fire: A review, Tunnelling and Underground Space Technology, 85, 2019, Pages 149-159

7. Velichkova R., I. Antonov, K. Nikolov, K. Grozdanov, M. Uzunova, Modeling of the occurrence of fire in closed cars garages, EFEA'2016, Belgrade, Serbia, DOI: 10.1109/EFEA.2016.7748807

8. Victoria Kroll, David Crundall, Aperture judgement in fire-appliance drivers, Transportation Research Part F: Traffic Psychology and Behaviour, 63, 2019, Pages $55-66$

9. X. Deckers, S. Haga, N. Tilley, B. Merci, Smoke control in case of fire in a large car park: CFD simulations of full-scale configurations, Fire Safety Journal, 57, 2013, Pages 22-34

10. https://carbrain.com/Blog/what-is-frame-damage 